\title{
Organização e Mecânica Administrativa das Emprêsas Públicas
}

\author{
MANOEL DE OLIVEIRA FRANCO SOBRINHO \\ Professor de Direito Administrativo da \\ Universidade Federal do Paraná
}

Com a tutela autorizada por um princípio legal superior, as emprêsas públicas que não são muito novas expressões de pessoas administrativas, se constituem em modos peculiares de gestão dos serviços públicos.

Há uma profunda vinculação fática entre as emprêsas públicas e os serviços públicos: com atribuições de interêsse geral, não obstante a personalidade privada, jamais contrariam elas os interêsses estatais na chamada Administração indireta.

Quando o Estado cria emprêsas públicas, ou organiza serviços que delega às pessoas privadas, está usando daquele poder que BUTTGENBACH denomina de tutela e administração. ${ }^{1}$

Não prevalecem as implicações doutrinárias sempre que a manifestação da vontade estatal fôr expressa e válida, clara na determinação dos limites da autonomia do serviço descentralizado.

Num trabalho cuja importância é incontestável, CONFALONIERI justifica essa nova exigência que se ampara no desenvolvimento econômico e no interêsse do Estado pela emprêsa industrial. 2

Para o economista italiano, ocorre a necessidade de mobilizar fôrça pública e privada, no sentido inclusive da competên-

1. André Buttgenbach - Théorie Générale des Modes de Gestion des Services Publics en Belgique - pág. 198.

pág. 26 . 
cia técnica em favor de certos setores de organização administrativa. ${ }^{3}$

Com mais precisão, atendendo à estrutura do serviço público orgânico, BUTTGENBACH em acôrdo com LOUIS ROLLAND recomenda que não se confundam as emprêsas privadas com as emprêsas públicas de interêsse geral e que são comuns às categorias administrativas. ${ }^{4}$

As similitudes por acaso existentes não contradizem com a personificação jurídica dos serviços administrativos exercitados em razão da teoria geral do serviço público. ${ }^{5}$

No tocante às emprêsas públicas não se pode teòricamente excluir o interêsse do Estado, a dependência do organismo à organização estatal pela sua natureza de conteúdo jurídico.

Ao lado do interêsse estatal que é público, há um interêsse jurídico que é o da forma que melhor convém às emprêsas privadas e aquelas de serviço público.

Tão reais se tornaram as emprêsas públicas na organização administrativa do Estado moderno que a ninguém mais preocupa a intervenção do tesouro na formação do capital social.

Conseqüentemente, colocadas como estão na Administração indireta, ainda recebem financiamento e recursos da fazenda pública como e quando a lei assim determinar.

$E$, no entanto, a autonomia financeira é a condição sine qua non de êxito e garantia de eficiência, desde que sem autonomia injustificam-se as emprêsas públicas na ordem administrativa.

\section{§ 10 - O SERVIÇO PÚBLICO ORGÂNICO}

Construindo a sua teoria do serviço público, já em 1923 CARLOS GARCIA OVIEDO afirmava ser êle "el eje sobre que gravida el moderno derecho administrativo". 6

Nada mais exato em fins dêste século:

- "determinar su noción, las normas juridicas que le presiden, las relaciones de derecho que origina, el régimen de su creación y organización".

3. Confalonieri - ob. cit., págs. 26 e segs.

4. Buttgenbach - Structure Sociale du Service Public Organique ob. cit., págs. $31 / 3$.

5. Buttgenbach - ob. cit., pág. 34 .

6. Ver La Teoría del Servicio Publico - pág. 5. 
São os pormenores indispensáveis de um sistema que dá o que de essencial existe no Direito Administrativo. ${ }^{7}$

Muito antes, ADOLFO POSADA, ainda no século passado, escrevia que a função administrativa se resolve concretamente em serviços e que a Administração é um sistema de serviços. ${ }^{8}$

Assim entendendo tôda relação de Administração resulta da ação de atividade do Estado que se realiza por intermédio de pessoas na medida em que crescem e multiplicam as necessidades públicas.

Com a transcendência do conceito e o aumento das funções estatais, ganhou realce não só a importância dos serviços departamentais administrativos, mas tôda uma série de complexas atividades que fora do Estado se prestam à satisfação das mais variadas necessidades.

O que parecia um exagêro de JËZE tornou-se em realidade no mundo atual: marcou o jurista francês época na história sòmente por dizer que o Direito Administrativo é o direito concernente aos serviços públicos. ${ }^{9}$

Considerado o serviço como uma atividade direta ou indireta do Estado, própria do poder público ou por êle delegada, no seu desenvolvimento histórico adquiriu conceito orgânico ou de organismo, passando a definir-se por um regime jurídico característico e peculiar. ${ }^{10}$

Muito bem pondera BUTTGENBACH:

- "Le caractère d'organisme administratif ou économique par lequel nous abordons la définition du service public organique n'envisage pas sa nature ou su régime juridique, mais uniquement sa structure sociale." 11

Com o avanço das técnicas modernas de administração, o serviço público tornou-se em missão do poder público: em missã̃o-função de prestar, fazer e executar alguma coisa que diga com o interêsse ou a necessidade públicas.

No seu conceito genérico de público o fim está sempre presente, como a pessoa que o realiza efetivamente, como a maneira de como é prestado e o regime jurídico que o regulamenta.

7. García Oviedo - ob. cit., pág. 5 .

8. Posada - Tratado de Derecho Administrativo - Vol. II, pág. 3.

9. A célebre obra de Gaston Jèze, Les Principes Généraux de Droit Administratif, fol publicada em Paris, no ano de 1914

10. Buttgenbach - Théorie Générale du Service Public Organique ob. cit., pág. 31 .

11. Buttgenbach - ob. cit., pág. 36 . 
Em sentido amplo, menor importância tem a maneira de como é o serviço prestado, mas importa desde os ensinamentos de PRESUTTI que sejam atendidos aquêles prestados pelos órgãos estatais e também aquêles prestados pelos particulares ou entidades autônomas. 12

Quanto ao regime jurídico cabe ao Estado dizer qual êle seja tendo em mira os interêsses que são gerais e concretos, tanto no plano pròpriamente administrativo, como também no campo social, econômico ou político.

$\mathrm{Na}$ verdade, portanto, observado o corpo político de uma nação pela sua organização administrativa, pode-se dizer que na organicidade dos serviços está a sua regularidade e continuidade ou a obrigação de assegurar o seu permanente funcionamento. 13

No Brasil, como exemplos de estrutura orgânica, temos recentemente reorganizados os serviços ferroviários, de correios e telégrafos e a Caixa Econômica Federal, dentro em princípio garantidor da unidade estatal e sem quebra da personalidade peculiar.

Chegamos um pouco tarde à lição de HAURIOU, segundo a qual o serviço público é, entre outras especificações, um serviço técnico onde a atividade jurídica se associa à atividade técnica. ${ }^{14}$

No gênero serviço público estão hoje integradas as emprêsas públicas como entidades orgânicas, que participam na ação do Govêrno com respeito à intervenção do Estado na ordem econômica, para organizá-la em consonância com os princípios do equilibrio social.

\section{§ 2 - AS EMPRESAS PÚBLICAS COMO FENÔMENO DA NOSSA EPOCA}

No relatório apresentado ao Congresso Internacional de Ciências Administrativas, realizado na França (Paris), em julho de 1965, NICOLA BALOG enfatizava:

- "As emprêsas públicas são consideradas, em todos os países, um fenômeno característico de nossa época", para dizer que,

12. Ver Instituzione di Diritto Amministrativo Italiano - Vol. I, pág. 202.

13. Buttgenbach - La Loi de Régularité et de Continuité du Service Public - ob. cit., pág. 77.

14. Ver Précis de Droit Administratif - pág. 44. 
1) êste fato é a conseqüência da expansão progressiva do setor público da economia, bem como da ampliação do seu papel, no curso dos últimos decênios, em particular nos países em desenvolvimento;

2) estas emprêsas fazem parte integrante da organização social e econômica dos Estados modernos, quaisquer que sejam, em geral, os fundamentos ideológicos e filosóficos sôbre os quais repousa sua estrutura sócio-econômica e jurídica; e

3) mesmo quando se trata de países cuja organização sócio-econômica é idêntica ou análoga, no que concerne aos conceitos, à extensão, ao papel geral e às funções, a expressão desta realidade varia condicionada pelas exigências do meio social. ${ }^{15}$

Não há dúvida para o administrativista iugoslavo NICOLA BALOG, ativo participante do congresso de Paris, que as emprêsas públicas onde existam se assemelham no que tange aos princípios e às técnicas, ${ }^{16}$ possibilitando comparações.

Ainda que nos países socialistas, como diz o professor de Belgrado, apresentem certo número de características, a diferença resulta da diversidade dos sistemas aplicados e que resultam da organização das atividades econômicas. ${ }^{17}$

Com respeito às formas jurídicas e de organização, ou dos meios de que a Administração dispõe para o cumprimento dos seus fins, ERNST FORSTHOFF lembra o seguinte quadro sistemático:

I - Administração soberana com meios próprios: a) diretamente através de organismo competente; b) por intermédio de um órgão administrativo autônomo de direito público;

II - Administração privatística com meios administrativos próprios: a) diretamente através de organismo competente; b) por uma pessoa jurídica que pode ser de direito privado. ${ }^{18}$

\footnotetext{
15. Nicola Balog - A Organização Administrativa das Emprêsas Públicas - RDA - 87/45.

16. "Mas tais diferenças, que resultam da diversidade dos sistemas aplicados, não tornam impossível certas comparações, notadamente no que tange aos princípios e às técnicas aos quais se tem recorrido para a organização das atividades econômicas, que, na hora atual, săo freqüentemente exercidas pelas emprêsas públicas." (Balog — trab. cit. - RDA - 87/45.)

17. No campo do Direito Comparado, considerando a contribuição estatística, é de lembrar o trabalho de Antônio Confalonieri, aqui citado e editado em Milăo, no ano de 1963.
}

18. Ver Tratado de Derecho Administrativo - pág. 527. 
É com certa razão, o que serve para dar posição à emprêsa pública no direito comparado, que FORSTHOFF fala em Direito de organização em sentido amplo, por onde a relação jurídica afeta todos os fenômenos de organização dentro da esfera estatal. 19

Isso implica em constatar que a emprêsa pública é uma forma de organização da Administração, sendo a sua atividade também administração no sentido funcional. ${ }^{20}$

Tudo muito simples: a emprêsa se chama pública quando mantida pela Administração pública, como quer FORSTHOFF.

Mantida sem personalidade jurídica própria, como instituição pública com capacidade de direito ou como sociedade com capacidade jurídica de direito privado. ${ }^{21}$

\section{§ 3 ? - A TEORIA ECONÔMICA DO SERVIÇO PÚBLICO}

Vale aqui lembrar, como argumento válido de esclarecimento históriço, a posição assumida por HENRY LAUFENBURGER:

- "A maior parte dos juristas emprega a palavra serviço público no sentido o mais amplo. Para uns, como JEZZE, compreende todo Direito Administrativo. Em sua acepção jurídica, o serviço público corresponde a uma necessidade geral administrativa ou política da coletividade e que requer proteção no sentido do interêsse geral". ${ }^{22}$

Não é sem razão, pois, que GUSTAVO CASSEL, aponta a diferença essencial que existe entre os modos, econômico-social e econômico privado de manejar os problemas econômicos. ${ }^{23}$

Essa diferença, para CASSEL, é realmente tão grande, que uma posição perfeitamente correta na economia privada, pode ser absolutamente falsa caso adotada na economia social. ${ }^{24}$

Por exemplo:

- para o indivíduo (emprêsa privada ou particular), é, sem dúvida, vantajoso possuir mais dinheiro, para uma sociedade (emprêsa pública) não, pois "muito do que é possível do ponto

19. Forsthoff - ob cit. - págs. 545 e segs.

20. Forsthoff - ob. cit. - pág. 659

21. Forsthoff - ob. cit. - pág. 663

22. Ver La Intervención del Estado en la Vida Economica - págs. 32/3.

23. Ver Pensamientos Fundamentales en la Economía - pág. 14.

24. G. Cassel - ob. cit., pág. 14. 
de vista da economia privada, será impossível quando se estenda ao conjunto da economia social". ${ }^{25}$

Não é de agora, portanto, que o Estado deve proteger o interêsse público e geral, sempre que a iniciativa privada se demonstre incapaz de assegurar à coletividade a satisfação das suas necessidades.

Por serviço público, na sua acepção econômica, entendemse aquelas satisfações imateriais, exigiveis de uma maneira permanente e constante, mas sempre vinculada ao exercício normal de uma necessidade imaterial de interêsse geral. ${ }^{26}$

A lição que se depreende da experiência, considerando a ação das emprêsas públicas com respeito às causas econômicas, torna evidente $o$ aspecto ofensivo e a atividade estimulante do Estado para a organização de serviços marcadamente inscritos na ordem econômica.

Não se trata pròpriamente de intervenção na estrutura econômica, tampouco de intervenção nacionalizante dos meios de ação econômica, mas de integração do Estado no domínio privado influenciado por considerações de serviço público.

Franqueia-se, assim, no dizer de LAUFENBURGER, a fronteira do domínio privado ao amparo do monopólio público, como finalidade de direção e orientação em determinados setores. ${ }^{27}$

Com êsse comportamento, o Estado atua econômica, material e moralmente, trazendo para os serviços públicos que sejam essenciais, condições que correspondam à economia nacional e ao bem público.

Para a chamada teoria econômica do serviço público, as emprêsas públicas não se podem perfazer conseqüentemente, sem que nelas se integre a vontade do Estado como poder econômico.

Êsse elemento, a vontade do Estado como poder econômico, é absolutamente essencial, isto é, integrante do próprio conteúdo orgânico jurídico das emprêsas públicas.

A tutela administrativa e a descentralização econômica passam a representar o melhor sistema ou o sistema mais adequado de conciliação entre a vontade do Estado e os interêsses gerais, coletivos e sociais.

25. G. Cassel - ob. cit., pág. 14.

26. Henry Laufenburger - ob. cit., pág. 33.

27. Laufenburger - ob. cit., pág. 243. 
Os elementos oferecidos, para a configuração das emprêsas públicas no tocante aos serviços públicos, são os mesmos de que se valem as legislações no direito comparado.

Não podemos, quanto às emprêsas públicas, considerar apenas o problema de um ponto de vista exclusivamente doutrinário ou teórico, mas também de um ponto de vista concreto e prático.

Já lembrou LUIS DELGADO que o "Estado chama a si tarefas que poderiam ser executadas por outrem, considerando, ao fazê-lo, que não surge ninguém para executá-las ou para executá-las de maneira adequada e bastante". ${ }^{28}$

\section{§ 4 ! - O ESTADO EMPRESÁRIO}

Na relação administrativa está o sentido de dever, de obrigação, de obrigatoriedade no desempenho da atividade pública, o princípio da continuidade do serviço público.

É o que diz de igual forma CELSO ANTÓNIO BANDEIRA DE MELLO:

— "o interêsse público que à Administração incumbe zelar encontra-se acima de quaisquer outros e, para ela, tem o sentido de dever, de obrigação. Também por isso não podem as pessoas administrativas deixar de cumprir o próprio escopo, noção muito encarecida pelos autores. São obrigadas a desenvolver atividade contínua, compelidas a perseguir suas finalidades públicas." 29

Com efeito, um serviço público prestado pelo Estado não se torna público pelo fato de interessar coletivamente, mas pela circunstância de atender a fins que correspondam ao regime administrativo adequadamente estabelecido.

Importa as noções em que se embasa, o regime de direito que disciplina, as regras que o legislador adotar para reputá-10 ou não dentro das regras de direito privado ou público.

Assim para nós nasce a emprêsa pública, o Estado como empresário, tão-sòmente porque o legislador acolhe, "no sistema normativo que constrói, os princípios que deseja vigorantes". 30

28. Ver Autarquias: Função Social e Aspectos Jurídicos - pág. 62.

29. Ver O Conteúdo do Regime Jurídico-Administrativo e seu Valor Metodológico - RDA - págs. 89/20.

30. Celso Antônio Bandeira de Mello - trab. cit. - loc. cit. - 89/29. 
Partindo do geral para o particular, as emprêsas públicas serão sempre as geridas pelo Estado, "segundo formas e dentro de limites determinados", pois sua autonomia decorre de uma delegação de podêres operada pelo próprio Estado no quadro de seus podêres administrativos. ${ }^{31}$

Com respeito à autonomia de gestão ou de ação nada há que evidencie maior importância: pode a autonomia ser maior ou menor nos níveis legais, resultante que surge da conveniência do Estado quanto à extensão dos meios para a consecução dos fins previstos.

Não obstante o regime próprio de cada pais, a variedade das atribuições estatais conforme os sistemas políticos, não cabe desconhecer que a característica definitiva que informa o serviço público não é outra senão aquela de natureza empresarial.

Nessa característica está o elo entre o serviço público econômico com o serviço administrativo e político, impondo obrigações jurídicas às emprêsas e definindo a orientação que devem adotar.

Convém sublinhar, com o Estado empresário, dentro de um plano econômico geral, que as emprêsas públicas não são necessàriamente diferentes e nem se apresentam conflitantes na legislação comparada.

A posição estatal é sempre a mesma para os elementos jurídicos obrigatórios que formam as emprêsas públicas: são os efeitos que podem não ser iguais ou estar harmonizados, tendo em vista princípios de economia planificada face ação política de maior ou menor amplitude.

\section{§ 5 ? - O PROBLEMA DA AUTONOMIA}

Em tese, o poder de dar autonomia às emprêsas públicas, tendo em conta confiná-las às exigências do exato cumprimento dos seus fins, é tão-sòmente um problema de contrôle administrativo ou de tutela exercitável nos moldes que a legislação indicar.

$\mathrm{Na}$ autonomia está o contrôle que exige seja a Administração informada sôbre o comportamento das emprêsas, vinculando-se a autonomia ao princípio do contrôle administrativo ou tutela.

31. Nicola Balog - trab. cit. - loc. cit. $-89 / 35$. 
Não é aqui a autonomia princípio que favoreça a livre disponibilidade dos interêsses públicos, mas princípio que consagra atividade que cumpre a lei regular através da Administração.

Em larga conceituação, aceitando-se as emprêsas públicas como pessoas administrativas, criando o Estado essas entidades de interêsses públicos, impossivel será deixar de considerar o regime a que estão submetidas e que "fraciona a unidade de manifestação administrativa". ${ }^{32}$

No entanto, para bem caracterizar a autonomia, basta que a emprêsa pública seja entendida pela configuração da sua personalidade jurídica, tanto no plano civil, como no plano comercial e penal.

Já que o patrimônio das emprêsas públicas pertence ao Estado, cabe ao poder estatal não só dar a elas a forma de organização, mas a maneira pela qual a autonomia se vincule ao princípio da responsabilidade, que por sua vez está vinculado ao reconhecimento da personalidade jurídica.

O contrôle, no sentido da autonomia, tem por finalidade verificar a eficácia da gestão delegada e em razão de uma delegação de podêres expressamente determinada.

Não há dúvida, observando a legislação comparada hoje histórica, que a maior ou menor autonomia é matéria de conveniência, podendo ou não ser concedida, dependente da natureza da emprêsa, ou conforme os objetivos que lhe foram legalmente atribuídos. ${ }^{33}$

Explicitando melhor, na base do ato criador das emprêsas públicas, aparecem dois elementos: um de ordem administrativa e natureza estatal como manifestação de vontade pública e outro imperativo nascido da lei que reconhece a existência dessas entidades.

Dentro, portanto, do círculo jurídico determinado, a autonomia tem seu campo próprio para ativar-se, sem que nesse campo não se atendam as normas que se extrovertem da vontade do Estado.

O problema não consiste, certamente, em limitar a atividade das emprêsas públicas, mas em fazer que a vontade estatal planificada garanta-a boa execução permanente dos serviços públicos.

32. A expressão é de Celso Antônio Bandeira de Mello - trab. cit. loc. cit. $-89 / 21$.

33. Nicola Balog - trab. cit. - loc. cit. $-89 / 35$. 
As implicações do contrôle e a sua extensão não atentam contra os critérios da autonomia; variam de legislação para legislação, de país para outro país, se fazem conforme com os regimes jurídicos ou políticos, porque adequados às exigências naturais de tratamento econômico peculiar.

\section{§ $60^{\circ}-$ AS EMPRESAS PÚBLICAS NO PLANO DA REALIDADE COMPARADA}

Há uma multiplicidade de posições jurídicas para o entendimento das emprêsas públicas no plano internacional da realidade político-econômica comparada.

Pode mesmo dizer-se que não existe um único sistema ou uma única doutrina procurando explicar tipològicamente as diferentes posições assumidas pelo Estado no que tange à criação de emprêsas públicas.

Num ponto, porém, as tendências se harmonizam diante da realidade comparada: na planificação que se tornou naturalmente obrigatória para o desenvolvimento da economia e setores dela.

Com a planificação como fenômeno administrativo normal ganham vulto os objetivos econômicos através das emprêsas públicas consideradas essenciais na execução dos planos econômicos.

Já antes de 1933, com o que FLEINER chamava de "moderna transformação do Direito constitucional", era possível conceber-se a ampliação da esfera de competência das autoridades administrativas até fora pròpriamente da matéria administrativa. ${ }^{34}$

Recorda o jurista alemão as decisões que em forma de lei emanam dos órgãos legislativos com o objetivo de organização das chamadas emprêsas de interêsse público, permitindo às autoridades legislativas participarem diretamente da Administração. ${ }^{35}$

A larga experiência foi anotada por CONFALONIERI em nações de organização política diferenciada, como a França, Grã-Bretanha, Estados Unidos, Austria e Itália, com a apresentação de resultados sobejamente conhecidos e bastante satisfatórios. ${ }^{36}$

34. Ver Instituciones de Derecho Administrativo - pág. 15.

35. Fritz Fleiner - ob. cit., pág. 15.

36. Antonio Confalonieri — ob. cit. - Introduzione - págs. 7 e segs. 
Apenas conotações díspares se apresentam quanto à feitura do estatuto jurídico que rege essas emprêsas, ou melhor, quanto às suas condições jurídicas, econômicas e financeiras que possam realmente constituir o quadro no qual atuam o contrôle e a gestão administrativa.

\section{$\S 77^{\circ}-\mathrm{A}$ COMPETENCIA LEGISLATIVA}

Considerando que a competência para declarar o direito seja aquela que é própria das autoridades legislativas, ressaltese a grande diversidade com relação à organização interna e a gestão das emprêsas públicas, inclusive com respeito à estrutura dos órgãos administrativos ou de gestão de nível superior.

Apesar do problema, afirma BALOG que podem ser discernidos certos grupos gerais, dentro dos quais todos os tipos de emprêsas públicas podem ser classificados a grosso modo, distinguindo-se três categorias principais, que compreendem:

a) as emprêsas cuja direção de nível superior é organizada como a das sociedades comerciais privadas;

b) as emprêsas que têm, à sua frente, um conselho de administração; e

c) as emprêsas dirigidas por uma só pessoa, como as que predominam nos países socialistas. ${ }^{37}$

Mas nunca é possivel ampliar a competência da Administração, sem que se ditem disposições de caráter geral e também particular para tarefas certas de efeito público-administrativo.

Não basta a vontade do Estado para determinar o caráter jurídico de uma emprêsa pública, caso êsse caráter jurídico não encontre amparo na competência legislativa.

A circunstância de que uma determinada emprêsa seja qualificada como não-industrial, não prejudica a lei na sua faculdade de submeter o direito privado a relações públicas especiais.

A regra da competência legislativa que deve ser geral não invalida a Administração na sua faculdade de gestão e autoridade ou na prática legal de direitos e obrigações.

Aqui no caso das emprêsas públicas, a Administraçăo aproveita dos meios jurídicos que a lei coloca à sua disposição,

37. Nicola Balog - trab. cit. - loc. cit. $-90 / 30$. 
como há pôsto pelo Código Civil à disposição das pessoas privadas.

$\mathrm{Na}$ verdade, é através da competência legislativa que o direito público e o direito privado se harmonizam, se interpenetram e se complementam, em face de relações que são jurídico-públicas.

Não fôsse o Estado constitucional moderno um Estado de direito escrito e portanto legislativo, o sistema, quem sabe, outro fôsse, onde a presença legal não apresentasse tanta importância, tornando, assim, possivel, que as emprêsas públicas só possuíssem estrutura administrativa.

\section{$\S 8 \div-$ A ESTRUTURA DAS DIFERENTES EMPRESAS PÚBLICAS}

No exemplo das emprêsas públicas geridas como sociedades privadas (existem no Brasil, França, Israel e Áustria), a legislação procura o retrato das sociedades por ações.

A emprêsa é quase sempre administrada por um conselho de administração, composto de número incerto de membros com mandato por tempo certo variável, em regra conforme a lei recomendar.

Dentro da tradição e da boa técnica administrativa, à frente do conselho há a figura de um presidente: recomenda-se essa figura pela necessidade da centralização e do contrôle interno.

Releva notar, apenas por motivo de prudência, que os modos de designação dos órgãos diretivos ou dos membros de direção não são os mesmos, variando de nação para nação.

O que importa, na estrutura das diferentes emprêsas públicas, são as funções exercidas e por lei delegadas.

Os critérios consagrados, de nomeação ou de escolha diretivas, não assumem qualquer importância no aparelhamento administrativo.

Em matéria de contrôle das operações, as emprêsas públicas dispõem de instrumentos próprios; com raras exceções que surgem do direito comparado, êsse contrôle é exercido por órgãos de fiscalização geral interna encarregados da normalidade administrativa.

Buscando analisar a situação nos países que recorreram ao recurso das emprêsas públicas para descentralizar serviços, apenas evidencia-se a sensível diferença de órgãos e métodos de contrôle. 
Além dessa diferença que é de capacidade, de direito e de fato, as emprêsas públicas como pessoas administrativas apresentam traços característicos de atividade vinculada ao poder estatal.

São os traços característicos de atividade vinculada que diferenciam cada estrutura de cada emprêsa pública, considerado de plano o regime jurídico assentado no sistema políticoadministrativo.

\section{§ 99 - O CONTRÔLE ADMINISTRATIVO}

Como pessoas administrativas as emprêsas públicas na sua base estrutural possuem:

a) podêres de direito público;

b) atividade administrativa impessoal;

c) competência de direito público;

d) extensão medida de poder;

e) direito subjetivo à competência;

f) atribuições incumbentes delegadas; e

g) reserva legal de autonomia.

Surgem elas:

19) como manifestação da descentralização governamental;

2:) como forma de pluralização ou divisão do trabalho administrativo; e

3ํ) como espécie de multiplicação de órgãos públicos de natureza privada.

Daí, necessàriamente, diante da administração central, no que concerne à organização das emprêsas públicas, o contrôle interno e a tutela administrativa.

Quando se apresentam como pessoas jurídicas criadas pelo Estado, porém funcionalmente distintas dêle, supõem subordinação de hierarquia administrativa indispensável à unidade estatal.

Como explica BALOG, no México, os principais meios de contrôle são os relatórios financeiros, as contas orçamentárias e os dados estatísticos. ${ }^{38}$

Em regra geral, tanto nos países socialistas como nos países de economia dirigida ou liberal, os elementos de contrôle

38. Trab. cit. - loc. cit. $-90 / 50$. 
se assemelham através da apreciação da legalidade das contas financeiras.

A par, portanto, da relação de administração, coexistem quase invariàvelmente,

19) o contrôle interno; e

29) a tutela administrativa.

Tendo em vista as regras jurídicas de onde procedem as emprêsas públicas, conclui-se que a condição existencial delas relativamente ao Estado é uma posição filiada ao conceito de serviço público.

\section{$\S 10^{\circ}-\mathrm{A}$ TUTELA DO CONTRŌLE EXTERNO}

França: o contrôle externo é exercido jurisdicionalmente pelos Ministros e pela chamada Comissão de Verificação das Contas das Emprêsas Públicas.

Rússia: o contrôle externo está sujeito anualmente ao Conselho de Economia Nacional, verificando-se a legalidade das operações pelos órgãos jurisdicionais estatais de contrôle.

Estados Unidos: o contrôle externo é o exercido pelo Congresso, pela Presidência ou pelos órgãos controladores do orçamento e verificadores gerais das contas.

Brasil: o contrôle externo é administrativo e jurisdicional, considerando o que obrigatório ficou por lei, em geral com o exame das contas pelo Tribunal de Contas da União para cada exercício.

Como tônica comum, o Estado influi sôbre a gestão das emprêsas públicas numa influência manifesta que quase se identifica assemelhando sistemas e regimes jurídicos, objetivando no plano econômico geral os programas adotados de desenvolvimento.

A intervenção estatal pode aumentar ou reduzir a atividade das emprêsas públicas, sobretudo no que diga respeito ao contrôle interno e à tutela administrativa.

A questão do contrôle externo, principalmente, em sintonia com a autonomia e a independência das emprêsas públicas, está vinculada ao problema legal ou aos limites que a lei determinar. 
Estamos com BALOG:

- "quase não há diferenças essenciais entre os diversos países, no que concerne à constituição das emprêsas públicas". ${ }^{39}$

Está na lei, ou é o legislador quem diz, sôbre o tipo de emprêsa pública a adotar, estabelecendo-se critérios de responsabilidade, de contrôle e de tutela.

Mas o fato possível de existirem diferentes tipos de emprêsas públicas não implica na inexistência do contrôle externo: as regras jurídicas, apesar das variações, estabelecem sempre que a tutela importa na fixação de responsabilidade que define direitos e obrigações.

$\mathrm{Na}$ maioria dos países mostra-se a constância da tutela do contrôle externo, pois sempre é o legislador (ou a lei) que impõe a forma em razão das exigências de fatôres peculiares.

É necessário, porém, considerar na ordem jurídica as implicações de natureza política: implicações que alteram em têrmos relativos a limitação ou a extensão do contrôle externo.

Uma conclusão salta lógica da análise comparada: a forma-estatutária-jurídica das emprêsas públicas quanto à tutela não é outra senão aquela definida por lei.

\section{$\S 119$ - PRINCIPIOS E OBJETIVOS}

No Brasil, as emprêsas públicas que já existem são tôdas sociedades de direito privado submetidas às normas do Direito Comercial e orientadas pelo Direito Administrativo.

Pontos há que ressaltar:

a) o regime financeiro é condição do estatuto jurídico;

b) o capital é aquêle atribuído pelo Estado através de condição legal;

c) o patrimônio é público-estatal;

d) as atividades comerciais visam o lucro;

e) a não-rentabilidade pode ser suprida pelo Estado por motivo do interêsse público;

f) sob o ângulo do interêsse público produzir lucro não é finalidade essencial;

39. Trab. cit. - loc. cit. $-88 / 41$. 
g) o lucro produzido importa quando reinvestido que satisfaça as necessidades e fins do serviço;

h) o plano das emprêsas públicas é plano de economia nacional e global;

i) os fins econômicos se harmonizam com os objetivos políticos.

Nas emprêsas públicas prevalecem:

19) de maneira direta os fins econômicos e os objetivos políticos; e sociais.

29) de maneira indireta os fins financeiros e os objetivos

Quanto aos objetivos políticos são êles fundamentais em qualquer país que pretenda assegurar o equilíbrio ou a independência econômica.

São considerados como princípios de importância nacional principalmente nos países socialistas ou nos países onde o capital estrangeiro se conflita com os interêsses econômicos nacionais.

Em qualquer nação as emprêsas públicas pretendem, em princípios e objetivos jurídico-estatutários, colaborar no plano político para o desenvolvimento econômico e social.

Por essa razão cabe ao Estado obediência aos preceitos do Direito Administrativo, coordenar êsses princípios e objetivos em defesa da execução de uma política econômica de regra governamental.

Inclusive com respeito às atividades econômicas não lucrativas que digam com o interêsse público ou afetam a harmonia necessária do desenvolvimento social.

\section{$\S 12^{\circ}$ - A EXTENSÃO DO DIREITO ADMINISTRATIVO}

Não era preciso que reafirmasse SCHWARTZ ser o Direito Administrativo "o desenvolvimento jurídico mais notável do século XX, refletindo na lei a hegemonia do setor executivo do Govêrno". ${ }^{40}$

40. "Na verdade, tão importante para o estudioso do Direito Administrativo quanto a tremenda extensão de sua matéria, é o amplo interêsse público demonstrado por ela nos últimos anos." (Bernard Schwartz - Direito Constitucional Americano - pág. 346.) 
Administrativistas ilustres, como por exemplo BASAVILBASO, limitaram-se ao método clássico de conhecimento dos problemas administrativos, sem bem compreender a sua manifesta evolução. ${ }^{41}$

Não se admite exclusão mais do contrôle governamental das atividades particulares que pretendem a satisfação das necessidades coletivas, mesmo que a Administração conceda ou delegue podêres.

\section{Mas nisto acerta BASAVILBASO:}

- "la conversión de los servicios publicos impropios o empresas reglamentadas en servicios publicos propiamente dichos, depende de la voluntad del Estado." ${ }^{2}$

Bem entendendo os serviços públicos em razão da satisfação das necessidades coletivas, a atividade direta ou indireta da Administração Pública transforma-se em conceito primeiríssimo.

Não só a vontade do Estado de ser considerada, mas também a realidade imposta pelo interêsse coletivo como fator preponderante para a harmonia da ordem jurídica em determinado regime político.

Quanto à expressão atividade, na prática corresponde a ação e prestação ao mesmo tempo, sem as obrigações de policia que BIELSA entendia indispensável para a defesa da ordem pública. ${ }^{43}$

Não resta dúvida que a atividade administrativa (públicopolítica) é uma atividade estrutural: de unidade na diversidade, de pluralidade na unidade, consubstanciando o interêsse geral que em nada diverge da necessidade geral ou necessidade coletiva.

Irrelevantes as distinções conceituais para ajuizar situações que finalisticamente são idênticas no sentido de pretender-se separar o que é coletivo do que é geral, o que é interêsse do que é necessário.

Para o Direito Administrativo moderno, na sua extensão de atividade real e ampla, tanto o processo de direito público como o processo de direito privado são instrumentos jurídicos hoje normais, regulares, indispensáveis, vinculados à estrutura constitucional.

41. Benjamin Villegas Basavilbaso - DERECHO ADMINISTRATIVO Análise de los Elementos esenciales del servicio publico - Vol. III - páginas 50 e segs.

42. Basavilbaso - ob. cit. - Vol. III - pág. 51.

43. Ver DERECHO ADMINISTRATIVO - Vol. I - pág. 156. 
Falando em processo de direito público, não se está enfàticamente excluindo o processo de direito privado: ambos os processos apenas se distinguem por um regime jurídico especial sem que a Administração queira subordinar interêsses particulares ao interêsse geral. ${ }^{44}$

Estão aí flagrantes os exemplos das fundações (que alguns querem públicas) e das emprêsas públicas: ambos os institutos instrumentos de processo privado através dos quais assegura 0 poder público a satisfação das necessidades coletivas.

\section{$\S 13^{\circ}$ - DESENVOLVIMENTO E MODOS DE SERVIÇO}

A extensão dêsse domínio do Direito Administrativo não se constitui numa questão caracterizadora da ação dos Executivos fortes: acentua-se, qualquer seja a estrutura constitucional-política, pelo próprio desenvolvimento no campo de atividade dos podêres públicos.

Tanto haja para as emprêsas públicas o contrôle parlamentar ou o contrôle jurisdicional, pràticamente elas se criam e se conduzem por iniciativas legais tomadas em virtude da influência econômica sôbre as atividades governamentais e administrativas.

Quer isso dizer que, não obstante a importância do contrôle, não falando em transferência de responsabilidade, as iniciativas tomadas visam planos a atingir a plenitude da vida econômica.

É papel do Executivo a intervenção pelo Estado em domínios cada vez mais técnicos e que atuam cada vez mais profundamente na vida econômica: não basta que os instrumentos de ação se limitem ou se restrinjam a graus mínimos de formulações, especialmente no âmbito da ação governamental.

Administração e desenvolvimento são expressões atualmente conjugadas para um mesmo fim, dentro em tendência onde a intervenção legal do Estado possa multiplicar iniciativas não só monopolísticas, mas iniciativas que resultem da pressão marcada pelo interêsse geral.

44. Não se trata, em parte agora contrariando a lição de Gaston Jèze, de distinguir o regime jurídico especial do processo de Direito Comum (Ver Les Principes Généraux du Droit Administratif - Vol. I - pág. 15), mas de demonstrar pela prática o que o Direito Administrativo moderno amplia executòriamente para atingir a plenitude dos fins estatais. 
A ação da Administração manifesta-se, sobretudo tècnicamente, numa gama de tendências que procuram encontro com o desenvolvimento, na elaboração de programas de estabilidade e de continuidade que em nada contrariam as relações jurídicas indicadas pelo Direito Administrativo na variedade das suas implicações de ordem jurídica e natureza econômica. ${ }^{45}$

O progresso da Administração tem sido rápido porque não opera ela com elementos equívocos: acelerada pela dinâmica social, pela massificação e tecnização, obriga os governos a considerá-la como instrumento lógico-econômico, que não pode expressar-se senão através de um comportamento operacional prático e fundado na pressão da realidade.

O encontro da Administração com a Economia e a Sociologia transforma-se num encontro de trabalho administrativo, por onde os preceitos pragmáticos assumem visualização investigatória do contexto social ou de conhecimento científico da estrutura das instituições.

A capacidade de ver o fato nôvo quando ainda em plena evolução e de perceber-lhe a importância tem sido uma constante do pensamento jurídico: no estudo da relação jurídica entre direito, economia e sociologia, está a explicação da realidade móvel em que vive o Estado.

Para PEDRO DELFINO o fenômeno administrativo se expande do setor privado ao setor público, tornando difícil entender a Administração isolada do contexto social. ${ }^{46}$

GARCIA OVIEDO já antecipava em 1923:

- "en la organización de los servicios publicos debe, pues, el Estado realizar una labor de equilibrio, de ponderación, respetando la iniciativa y competencia de las fuerzas individuales, pero mostrando su actuación en todas aquellas esferas a que dichas fuerzas no alcancen. Es, por lo demás, una necesidad inexcusable del sistema económico que rige al mundo moderno." 47

Um variado estudo publicado no Brasil pelos idos de 1959 levanta os mesmos problemas executório-administrativos que são nacionais, numa demonstração de que os propósitos gover-

45. Ver Pedro Delfino - Administración y Desarrollo - La Plata, 1970.

46. Delfino - Introducción a la Teoría de la Administración - páginas $46 / 7$.

47. Ver La Teoría del Servicio Publico - pág. 33. 
namentais se identificam por fôrça de uma política de satisfação dos interêsses coletivos. ${ }^{48}$

Mas foi precisamente BUTTGENBACH quem ampliou a visão jurídica das necessidades coletivas, publicando a sua teoria geral dos modos de gestão dos serviços públicos na Bélgica, com a preocupação de personificar os serviços públicos administrativos, ou de dar significação à responsabilidade governamental quando no exercício dos podêres de tutela. ${ }^{49}$

Não há boa doutrina que não possa hoje entender que o desenvolvimento exige novos modos e novas atitudes, desde quando o Estado busca pelo processo privado os meios mais capazes de com rapidez fazer funcionar serviços essenciais, mesmo abandonando as regras tradicionais.

\section{$\S 149$ - O PAPEL DA ADMINISTRAÇĀO}

Já insistimos com o caráter público dos organismos administrativos (ou lato sensu pessoas administrativas), com aquêle sentido que Ihes dá BUTTGENBACH de integração no Estado que

- "distinquent no seulement de l'entreprise privée mais aussi du service public virtuel ou de la gestion privée des services publics." 50

Não é, porém, pela distinção, que se exclui o papel da Administração, quanto às fundações, e, principalmente, quanto às emprêsas públicas criadas, organizadas e orientadas pelo Estado.

Constata-se que a realidade é mais forte na combinação daquelas exigências econômicas harmonizadoras do regime jurídico com a estrutura pròpriamente orgânica e social do Estado.

Não se argumente com a liberdade de comércio e de indústria expressa como princípio nos textos constitucionais, tãosòmente porque os serviços monopolizados (telecomunicações, correios e telégrafos e Caixas Econômicas) são atividades reservadas ao poder público.

48. J. Djordjevic, J. W. Grove, J. E. Rodgetts, A. lojrich, Pierre Laroque, Roy C. Macridis e Jean Meynaud - O PAPEL DO EXECUTIVO NO ESTADO MODERNO - Revista Brasileira de Estudos Políticos - Rio, 1959.

49. André Buttgenbach - ob. cit. - Prefácio de Henri Matton Bruxelas, 1959.

50. Buttgenbach - ob. cit. - pág. 35 . 
São serviços que objetivam diretamente a unidade e que não podem evidentemente sofrer nem excepcionalmente delegação legislativa através de privilégios que atentem contra 0 geral interêsse público.

Transpondo a teoria geral das obrigações para o Direito Administrativo, num trabalho de profunda pesquisa que aproxima a causa em Direito Civil da causa em Direito Administrativo, MARCEL WALINE se fixa em considerações reconhecendo que há a necessidade de uma causa para a validade das obrigações assumidas pela Administração. ${ }^{51}$

Todavia, a causa no Direito Administrativo alcança, além do que pretende WALINE, efeitos na jurisdição administrativa que não se assemelham aos efeitos civis, tendo em conta que a extinção das obrigações decorre da lei e das condições obrigacionais que a lei determinar. ${ }^{52}$

As regras do Direito Civil, aplicadas nos casos concretos, tornam está claro a Administração responsável, mas não tiram do Estado sua fôrça de vontade compatibilizada sempre com o interêsse público maior.

No limite da competência exclusiva do legislador, obedecidos princípios determinativos que são legais, o serviço público é criado, organizado e suprimido, não importando qual seja 0 processo adotado ou os modos de gestão quanto aos fins e ao funcionamento.

A importância do papel da Administração depende, primeiramente, do seu poder regulador em virtude da incidência do tecnicismo nos casos de intervenção do Estado: certamente que a ação administrativa manifesta-se sobretudo onde haja a pressão contínua do interêsse público.

Sem dúvida, as emprêsas públicas (e as fundações), como categoria de órgãos descentralizados, refletem não só a oportunidade do serviço público, mas geralmente uma tendência a mobilizar a Administração com maior segurança e melhor conhecimento das necessidades coletivas.

Outro fator essencial do papel que realiza a Administração está no regime jurídico que adota: criando as pessoas organiza uma divisão de competências entre o poder central e as entidades descentralizadas, divisão essa que não é pròpria-

51. Waline - TRAITÉ ÉLÉMENTAIRE DE DROI ADMINISTRATIF De la Cause en Droit Administratif - págs. 612 e segs.

52. Waline - ob. cit. - Titre III - pág. 621. 
mente uma partilha e nem um dualismo porque não prescinde jamais do contrôle ou da tutela legal.

\section{$\S 15^{\circ}$ - O FENÔMENO ADMINISTRATIVO}

Quanto ao fenômeno administrativo nem sempre é nôvo diante da história, porque:

a) funda-se num conceito de administração que isolar-se não pode do contexto social;

b) na dicotomia da Administração pública e privada reside tôda atividade estatal;

c) no dualismo administração e organização está a problemática do funcionamento e comportamento administrativos.

Aceitando certas técnicas juridicas, o que faz a Administração, considerada como fenômeno administrativo, não é outra coisa que aproximar-se de realidades aceitas e reconhecidas pelas ciências sociais ou pelo conjunto de conhecimentos já tradicionais.

Eis o motivo da razão de as emprêsas públicas estarem bastante aproximadas das emprêsas privadas industriais ou comerciais, e de adotarem a personalidade de direito privado.

Com essa aproximação, o Estado procura pela técnica estruturar um organismo administrativo como bem conceitua E. D. JONES, um sistema de administração que não constitui um fim em si próprio, porque o que pretende é pràticamente um instrumento de atuação. ${ }^{53}$

Como se falasse de emprêsas públicas, JONES lembra nas emprêsas privadas fins que são comuns com as emprêsas públicas:

a) orientação racional;

b) meios financeiros;

c) contrôle nos gastos;

d) organização de funcionamento;

e) competência na demanda comercial;

f) instalações econômicas necessárias;

g) recursos necessários adequados;

53. Eduardo D. Jones - Organización y Administración de Empresas Industriales - trad. esp. - pág. 194. 
h) relação de trabalho;

i) sistema administrativo baseado em métodos práticos e econômicos. ${ }^{54}$

Acontece, sem dúvida, que o fenômeno administrativo se apresenta como uma síntese: tanto pode ser admitido pelo Estado (Administração) como pelos particulares para a criação de produtos e serviços, não como finalidade concreta e sim como meio de atuação.

E compreensível, portanto, no tocante à organização dos serviços públicos, que os sistemas de administração se assemelhem sem quebra da indispensável relação jurídica ou de condições que em têrmos econômicos possibilitem equilibrio e coordenação no conjunto estatal.

Por outro lado, bem sentindo a realidade, o fenômeno administrativo está na gênesis do Direito Administrativo: aparece em expansão extrovertendo poder administrativo, surge em distensão aplicando princípios existentes, acontece sem violentar o direito constituído. ${ }^{55}$

Apenas a extensão do poder administrativo varia no sentido jurídico, segundo as relações no modo do exercício (meios) e do fim proposto (direção) por quem o exerce ou o institui. ${ }^{56}$

Não há como contrariar aqui BIELSA:

- "si en algún caso es inseparable el concepto de poder de la idea de derecho es precisamente en la esfera de la Administración publica." ${ }^{57}$

Já que o poder do Estado se exerce por maneiras diversas, na chamada administração indireta as normas administrativas para o funcionmento dos serviços públicos são na oportunidade técnicas e jurídicas, como no caso das fundações e das emprêsas públicas.

Apenas o fenômeno administrativo, quando se impõe aconselhado pela realidade, exige regulamentação de parte do poder

54. No Seminário de Rangum, outras não foram as recomendações. No entanto, anteriormente, E. D. Jones, já antes de 1942, estabelecia premissas de organização administrativa apontando modalidades de gestão para problemas de indoles diversas.

55. “... cuanto tienen de orgánico y sistemático algunas instituciones de derecho administrativo se debe a la técnica del derecho civil" (Rafael Bielsa - ESTUDIOS DE DERECHO PUBLICO - Génesis del Derecho Administrativo - pág. 25).

56. Bielsa - ESTUDIOS - pág. 31.

57. Bielsa - ob. cit. - pág. 31 . 
central, pois a entidade descentralizada não está fora do Estado, mas integrada a um órgão do Estado ou ao próprio Estado.

\section{$\S 160^{\circ}$ - VARIAÇÃO INSTITUCIONAL}

Segrêdo não é que as instituições variam fundamentalmente segundo as nações soberanas: com essa variação varia também - sistema de prestação dos serviços públicos.

Não obstante existirem tendências que são convergentes, os serviços públicos, quando prestados ou executados, apresentam peculiaridades que se evidenciam na organização e comportamento administrativos.

Daí, então, o motivo por que os serviços públicos refletem um sistema de organização política (administrativa) que se apresenta sob a forma da centralização ou da descentralização.

Cabe ao Direito Administrativo na área da variação institucional e dentro dos princípios da organização hierárquica dar estruturação (ou estudar) os órgãos, os meios de execução e de atividade estatal, personificando jurìdicamente os direitos subjetivos públicos.

O que importa ao Direito Administrativo (exemplificando-se com as fundações e as emprêsas públicas) é determinar o conteúdo da norma criadora dentro de um sistema orgânico de fins.

Mas a importância da Administração ativa reside nisto:

19) em aparecer no sentido material, como poder administrativo, órgão ou organismo; e atividade.

2?) em aparecer no sentido formal, como função, matéria

Tendo em conta a importância existencial da Administração ativa no seu conceito de construção política, há que considerar:

19) a necessidade do serviço público;

2) a natureza da função pública; e

3 ?) a responsabilidade do Estado.

De onde, por tudo isso, um argumento salta lógico: o da relativa aplicação do método e da técnica jurídicas.

Admitindo-se, assim, como já o dissemos anteriormente, que a análise do direito comparado é a mais conveniente, especialmente para o estudo das emprêsas públicas. 
Tanto das emprêsas públicas como serviço público, delas exercitando funções e do Estado (poder administrativo ou Administração no caso) responsabilizando-se através da tutela e do contrôle.

Claro está desde logo que o método aplicável com respeito às emprêsas públicas (e às fundações) deve sofrer um paralelo com a legislação comparada para a definição dos princípios orgânicos.

Como em tempo observamos, o regime jurídico pode nem sempre ser o mesmo: as diferenças que existirem consistem naquilo que constitucionalmente é permissível ou no específico jurídico do ato administrativo.

Há nas emprêsas públicas, em virtude da variação institucional, uma necessária discriminação da atividade administrativa em correlação com os fins do próprio Estado.

Revelam, se melhor examinadas, as emprêsas públicas (como as fundações), caracteres específicos de serviço público.

Nelas, emprêsas públicas ou fundações, o fim público ou a gestão dos interêsses públicos, não obstante a variação institucional que é circunstancial, apresenta, pela personalidade jurídica expressamente estabelecida, característicos bastante peculiares.

No entanto, prevalecem alguns elementos constitutivos essenciais, que são por assim dizer gerais:

19) o da personalidade que justifica a autodeterminação (autonomia) sob contrôle tutelador; $e$

2)) a criação legal. ${ }^{58}$

Basta, porém, o fundamento, a forma e o exercício da tutela, o grau e a natureza do contrôle administrativo, ou então da intervenção estatal, para desde logo determinar-se os pressupostos jurídicos que definem as emprêsas públicas perante 0 direito comparado.

É atualmente imprecisa e desconcertante a posição de BASAVILBASO quando considera a tutela administrativa sòmente válida para as pessoas jurídicas de direito público, estando as pessoas jurídicas de direito privado isentas de vigilância ou de tutela. ${ }^{59}$

58. Os relatórios do Seminário de Rangum levam à mesma conclusão. Inclusive os estudos aqui citados e de autoria de Nicola Balog.

59. Ver DERECHO ADMINISTRATIVO - Vol. II - pág. 113. 
Não prevalece mais a doutrina tradicional pelo menos com respeito às emprêsas públicas e às fundações: são elas, como organismos administrativos, pessoas jurídicas de direito privado, criadas pelo Estado e que existem e permanecem sob a tutela estatal.

\section{$\S 17^{\circ}-$ AS REALIDADES POLITICAS E AS VERDADES ECONÔMICAS}

Numa proposição geral que não é teorismo,

- "en qualquier empresa, publica o privada, que requiera el esfuerzo co-operativo, el liderazgo, la autoridad, responsabilidad y motivación, están involucrados en los objetivos de la administración..." conforme diz PEDRO DELFINO. ${ }^{60}$

Os dados experimentais demonstram, numa quase total indistinção doutrinária, que os princípios, conceitos, métodos ou técnicas estão na própria natureza da Administração. ${ }^{61}$

É DELFINO quem pondera:

- "el término dirección (management) reservado otrora a la gestión de la empresa privada o de negocios se utiliza hoy indistintamente para los asuntos publicos y el de administración es compreensivo de formulaciones politicas y de dirección". ${ }^{62}$

Todos os elementos que integram a "fenoménica administrativa" de que fala DELFINO, constituem um sistema: a Administração reúne todos os elementos e os sistematiza, em razão dos seus fins (objeto) e naturalmente dos seus componentes aqui para nós de conteúdo jurídico. ${ }^{63}$

Desnecessário será não concordar com o desdobramento das várias faces que assume a intervenção estatal: tôda estrutura social (e também econômica) sofre a influência da problemática administrativa envolvendo os problemas de bem-estar social-econômico. ${ }^{64}$

Em tese, êste poder de adequar as emprêsas públicas (e as fundações) aos objetivos estatais, tendo em vista integrá-los na estrutura da Administração ativa, não traduz prerrogativa: reflete claramente exigências do interêsse público para o cumprimento de obrigações do Estado para com os administrados.

60. Ver Administración y Desarrollo - pág. 159.

61. Pedro Delfino - ob. cit., pág. 159.

62. Delfino - ob. cit., pág. 159.

63. Delfino - ob. cit., pág. $\mathbf{1 6 0 .}$

64. Delfino - ob. cit., pág. 164. 
Tal procedimento, em perspectiva material e formal, depende mais do regime jurídico que pròpriamente do regime administrativo, pois não são os conceitos extra-jurídicos que perturbam o que houver decidido a lei, ou o que houver disciplinado o legislador.

Sobretudo nos tempos atuais, onde as realidades políticas se confundem com as verdades econômicas, onde os conceitos jurídicos se procuram harmonizar com o interêsse público e social, o ordenamento jurídico (para a Administração) não possui confronto senão com êle mesmo, ou senão com as manifestações vitais que extroverte, segundo MIELE. ${ }^{65}$

Compreende-se que o desenvolvimento econômico se ampare nās técnicas de um sistema jurídico, procurando através da supremacia dos órgãos da Administração tornar real as obrigações a que o Direito Administrativo responde pelos seus institutos.

\section{$\S 180^{\circ}-$ AS EMPRESAS PÚBLICAS NAS SUAS RELAÇÕES COM O ESTADO}

Sem maiores indagações, em se tratando das emprêsas públicas, afastado na sua relatividade o conceito de utilidade pública, a mais afeiçoada definição de serviço público é aquela enunciada pela orientação do pensamento de RUY CIRNE LIMA, como

- "todo o serviço existencial, relativamente à sociedade, prestada aos componentes daquela, direta ou indiretamente pelo Estado ou outra pessoa administrativa". ${ }^{66}$

Dispensável que, pela essencialidade, invoque-se o caráter econômico de muitos serviços públicos realizados na constância com a participação da Administração: são aquelas outras pessoas administrativas que aparecem como instrumento da execução estatal, inconfundíveis hoje como entidades qualificadas pela relação jurídica administrativa.

Tal noção, quanto à posição, expressa alcance de organização política no quadro complexo do poder administrativo: nos programas oficiais de cada nação há essa preocupação positiva e latente de alimentar os meios à necessária manutenção de serviços públicos tipificados.

65. Giovanni Miele - Principi di Diritto Amministrativo - Vol. I - pág. 81.

66. Ver Sinopse de Direito Administrativo Brasileiro - pág. 29. 
Considerando o avanço técnico, o Estado visa a dois grandes objetivos, que são os lembrados por KALACHEK:

- em primeiro lugar, estimular progressos úteis aos órgãos governamentais no desempenho de suas funções específicas;

- em segundo, fomentar o progresso a fim de beneficiar determinado setor ou a economia em conjunto. ${ }^{67}$

Sofre o Estado moderno um crescente poder de organização, eis que o progresso técnico (desenvolvimento) exige planos exeqüíveis que sirvam à comunidade ou condicionem o funcionamento racional da Administração em têrmos operacionais concretos.

A fôrça do Estado, portanto, é organizada em apoio dos serviços públicos, principalmente daqueles serviços de natureza econômica, de serviços que preparam a Administração para a tarefa primordial de equilibrio quanto ao bem-estar social.

Levado aos seus justos limites, limites que se definem pelo conteúdo das normas jurídicas, ou seja, pelos interêsses que direta ou indiretamente precisa tutelar, o Estado regula as suas atividades exercendo autoridade legal ou o privilégio legislativo.

Sem embargo, manipulando normas de direito privado como aparecem escritas na legislação, nada mais faz a Administração que proteger o interêsse público geral contra as flutuações da economia, relacionando-se com os institutos consagrados, sem exceder os limites das suas próprias e diferenciadas funções, ou atribuições administrativas.

JAMES M. LANDIS fala compreensivamente em concessão de poder administrativo: não existe mais exata expressão, no tocante às relações jurídicas, no que diz respeito com as emprêsas públicas (ou as fundações) quando exercem jurisdições de serviço impostas por lei. 68

Na situação contemporânea do Estado interventor, a posição mais realista é aquela que focaliza os problemas de administração em meio às normas jurídicas, quer privadas quer públicas.

Resta saber, com respeito às emprêsas públicas (e fundações), sob que formas e em que graus de limite devem ser fixados os podêres da Administração: tais são os problemas de natureza, personalização, fins e limites da atividade governamental.

67. Nelson Peck Kalachek - TECNOLOGIA E DESENVOLVIMENTO ECONÔMICO - Política e Instituições Públicas - pág. 175.

68. Ver El Poder Administrativo - pág. 49. 
Cada sociedade política organizada tem o seu próprio campo de ação administrativa, regime jurídico, normas de procedimento e processo, instituições e outras formas de expressão organizacional-político-jurídica, para responder às indagações do direito comparado.

\section{$\S 190^{\circ}$ - O FATO NA LEGISLAÇÃO E NA ADMINISTRAÇÃO}

Óbvio que é pela função legislativa que o Estado estabelece as regras gerais abstratas, mas que é através da jurisdição e da Administração que desenvolve a sua atividade individualizada ou personificada, ${ }^{69}$ relacionando legislação e execução, direito e administração.

Para a solução de certos problemas públicos (ou de serviço) é que surgem certas normas administrativas de aplicação geral ou particular, sob o regime jurídico melhor aconselhado.

De comum, onde existem as emprêsas públicas na sua expressão atual, surgem elas para preencher os claros no sistema econômico para a prestação dos serviços necessários à sociedade.

Sem entrar em análises que aqui não cabem, não é de estranhar que formas administrativas especiais sejam adotadas no sentido de harmonizar a eficiência administrativa com o interêsse público.

De acôrdo com a tendência dominante, aceitas as preliminares de critério jurídico, a Administração Pública hoje em dia não limita e não pode limitar aquelas condições que são ordenativas de organização, planejamento e contrôle para cumprimento dos propósitos públicos.

O critério jurídico, sempre relacional, não contrastando com as regras legais, como também não se conflitando com a aplicação do direito, não escapa da faculdade discricional. ${ }^{70}$

A compreensão das técnicas modernas influenciando a Administração vale pelas analogias que se podem levantar dentro de um legalismo largo e não estreito, numa demonstração da capacidade criadora do Estado, estimulante de melhor compreensão do processo econômico.

69. Ver Hans Kelsen - Teoría General del Estado - pág. 301.

70. Prova a alegação o longo e magnífico estudo de N. Balog com tanta oportunidade traduzido por Sérgio Andrea Ferreira, e publicado na Revista de Direito Administrativo. 
Observadas no seu contexto as experiências que se desenvolveram em condições políticas variáveis, as emprêsas públicas cuidadosamente estudadas mantêm variantes jurídicas que jamais prejudicam as situações concretas em que vivem e se desenvolvem.

Na maior parte das vêzes, as legislações nacionais se refletem na Administração, tornando sem importância os princípios normativos, de mecânica ou de organização interna das emprêsas.

Em síntese, num resumo de análise, salvo as variações de intenção política, os métodos jurídicos são os mesmos, não obstante amoldados às peculiaridades de valôres que são de direito interno.

O fato, como realidade, está no que impõe a legislação e no que executa a Administração: provocar resultados econômicos é a finalidade, compreender os problemas econômicos, o objetivo.

Para a Administração (ou o Estado) não só importam as práticas administrativas assentadas no regime jurídico, mas a disciplina dessas práticas em atendimento dos interêsses públicos e das necessidades sociais.

Conseqüentemente, a sistematização vem em auxílio da descentralização, oferecendo ao trabalho-administrativo-público formulações fora das fronteiras dos vários departamentos jurídicos e face à dinâmica complexa do processo econômico.

Do ponto de vista da estrutura, consideradas as dimensões políticas, não há como determinar-se padrões universais que perfeitamente se possam ajustar aos padrões nacionais, como veremos.

Nisso, contudo, atendendo às alternativas econômicas, as emprêsas públicas, na sua aparência de forma, estão identificadas, ensejando apenas ajustamento às condições de cada país.

\section{§ 20\% - REGIME ADMINISTRATIVO DOS SERVIÇOS PÚBLICOS}

Não é fácil, pelo menos por enqunto, fazer-se um estudo bem ordenado e conclusivo do chamado regime administrativo, em virtude da diversidade das organizações estatais-nacionais.

Não varia, porém, o conceito da emprêsa pública, mas pode variar a sua constituição e forma, inclusive a sua personalidade jurídica conforme o que a lei determinar. 
No entanto, essa personalidade jurídica, principalmente, não mais constitui tema de debate: a questão suscita qualquer preocupação porque o legislador internacional assim o decidiu, afirmando princípio que se tornou além de jurídico, orgânico e estatutário.

Essa questão, antes fundamental e controvertida, não apresenta agora distorções conceituais: a orientação privatística decorre de importantes conseqüências quanto à maneira de conduzir as emprêsas, a situação do pessoal funcionário e a atitude dos organismos de contrôle.

Embora a sensibilidade do legislador esteja no saber distinguir quando há precisamente serviço de caráter privado, ou quando haja necessàriamente serviço público, já o conceito atual de serviço público não se liga às regras estabelecidas de processo público.

Nos regimes administrativos modernos a questão deve ser examinada à luz dos princípios gerais do direito e dos textos legislativos: a natureza do objetivo depende do próprio objetivo, considerado em si mesmo, e não da forma pela qual o Estado possa intervir.

O vínculo relacional dá lugar a uma situação de fato que comunica o poder público com o processo privado no interêsse do serviço público: o elemento de processo privado aqui é indispensável tão-sòmente por não se poder excluir o Estado da sua função econômica.

Resultam, assim, as emprêsas públicas, de uma combinação de interêsses que se harmonizam com os fins (objetivos), permitindo-se ao poder público (Administração) controlar diretamente os serviços empresariais com propósitos essencialmente públicos.

Pode e deve, portanto, o Estado, na sua capacidade legislativa, aceitar o regime administrativo melhor aconselhado pelos fatos, submetendo sua ação ou atividade tanto aos meios específicos de processo privado quanto aos meios naturais de processo público.

Alcançou, neste século, ou de alguns anos para cá, o regime administrativo dos serviços públicos tal elasticidade, que não existem mais perspectivas de retôrno àquela política onde - Estado ficava à margem das soluções e das fórmulas de conciliação jurídica.

É, pois, natural, que o poder público assuma, através das emprêsas públicas (e das fundações), os encargos decorrentes do progresso social e econômico: tais encargos, em razão do 
serviço que é público, exigem adoção de regime-jurídico-administrativo adequado à prestação em melhores condições dos serviços públicos essenciais.

Daí porque as emprêsas públicas, além do privilégio na exclusividade da prestação do serviço, pela maioria das legislações está exonerada de direitos fiscais como impostos ou taxas, não obstante a indeclinável posição de pessoa jurídica de direito privado.

\section{$\S 210^{\circ}-$ CONCLUSÃO}

Saliente-se que, na maioria dos países, o Estado está chegando à exploração dos serviços de interêsse geral (ou públicos), perseguindo fins de alta política administrativa e econômica.

Não só as tendências do Estado moderno, mas as necessides de ordem administrativa, levam a Administração a explorar serviços com a intenção de os prestar com o máximo de eficácia ou rendimento.

Como as fundações, as emprêsas públicas, dentro dos objetivos que lhes são atribuídos, possuem uma estrutura legal preestabelecida, acentuando-se nelas a flexibilidade administrativa necessária às atividades das emprêsas industriais e comerciais.

Em quase tôdas as emprêsas públicas onde se encontrem, a gestão descentralizada fica sujeita à coordenação das operações através da planificação de meios e fins, do possível financiamento e provável investimento, assegurado pelo exercício do contrôle estatal.

Alguns princípios normativos gerais já estão no momento consagrados:

a) as emprêsas públicas são criadas e geridas pelo Estado, segundo normas e limites determinados em lei;

b) a autonomia decorre da lei e dos podêres que são delegados, dentro em sistema geral de Administração pública;

c) o Estado as organiza de modo a assegurar eficácia de gestão quanto aos meios e fins administrativos e econômicos;

d) a direção das emprêsas é aquela que convém à concepção política adotada de Administração pública.

Exemplo: nos países socialistas assentam elas no centralismo político e econômico quando atendem ao sistema so- 
cialista de produção ou o sistema de planificação da economia nacional.

Outro exemplo: nos países não-socialistas, no geral a importância do contrôle depende do interêsse que se manifesta econômicamente em razão da política estatal.

Tanto nos países socialistas como não-socialistas, a organização das emprêsas públicas repousa nos meios e fins estatutários, sem prejuízo da coordenação e da tutela estatais.

Considerada a concepção soviética de Administração, adotada pelas demais repúblicas populares, prevalece o princípio do chamado centralismo democrático, objetivando, pelo processo socialista de produção, subordinação que,

19) atende ao sistema global de planificação da economia nacional; e

2 ) ) atende a uma atividade produtiva determinada em função de princípios de economia popular.

Os princípios elementares nos países de organização socialista, são êstes:

a) centralismo democrático;

b) unidade de administração política;

c) unidade de orientação econômica;

d) planificação e contrôle financeiro;

e) propriedade pública socialista;

f) participação dos empregados (trabalhadores) na gestão das emprêsas.

Na maioria das nações não-socialistas, não há, por assim dizer, tendências formais claramente definidas: a posição das emprêsas públicas, no quadro geral da Administração, reflete manifestação legal ou a política seguida pelo Estado.

Quanto à responsabilidade está sempre entrosada à aplicação e respeito das regras estatutárias de direito privado, não obstante vinculações que possam ocorrer conseqüentes da peculiar organização legal, do contrôle ou da extensão do serviço público pretendido.

De um modo geral, pode afirmar-se que, quase sem discrepâncias, as emprêsas públicas são criadas e estruturadas em função de regime político próprio à organização administrativa estatal.

No Brasil, as emprêsas públicas mais recentemente organizadas trazem as características de plena autonomia sob contrôle específico, cabendo à Administração (Executivo) fixar as normas de direção e as diretrizes de funcionamento nos limites do poder regulamentar. 